\title{
STRENGTH AND DUCTILITY EVALUATION METHOD FOR STEEL BRIDGE PIER FRAMES CONSIDERING EFFECT OF SHEAR FAILURE
}

\author{
L. Kang ${ }^{1}$ and H.B. Ge ${ }^{2, *}$ \\ ${ }^{1}$ Post Doctoral Researcher, Dept. of Civil Engineering, Meijo University, Nagoya, 468-8502, Japan \\ E-mail: connielan@tom.com \\ ${ }^{2}$ Professor, Dept. of Civil Engineering, Meijo University, Nagoya, 468-8502, Japan. \\ *(Corresponding author: E-mail: gehanbin@meijo-u.ac.jp)
}

Received: 25 August 2011; Revised: 4 October 2011; Accepted: 21 November 2011

\begin{abstract}
This paper presents a practical evaluation method for predictions of strength and ductility capacity of steel bridge pier frames including effects of shear failure. The shearing behavior of structure is simulated by introducing membrane and truss elements at the mid-span of girder. In order to investigate the effects of shear failure on the strength and ductility capacity, a series of pushover analyses are carried out, comparisons between different methods are conducted and effects of sensitive parameters are discussed. From these investigations and discussions, the availability of the shear ductility prediction method proposed in this study is verified, especially for the unstiffened cases with large web width-thickness ratio of girder. Furthermore, a boundary between bending and shear failure modes is obtained based on discussions.
\end{abstract}

Keywords: Steel bridge pier frame, Shear failure, Bending failure, Ductility capacity, Membrane element, Web width-thickness ratio of beam

\section{INTRODUCTION}

Steel bridge piers suffered severe seismic damage during the Hyogoken-Nanbu earthquake, on January 17th, 1995. Some of steel bridge piers' failure during this earthquake mainly resulted from the shear local buckling, as shown in Figure 1. Severe shear damage in such structures caused considerable disruption to the relief work. This resulted in a consensus to be reached that the seismic capacity, especially the ductility, of such structures needs further and extensive investigation. Because no similar damage ever being reported in Japan before, shear failure, especially at the mid-span of girder, was not considered in seismic design prior to this earthquake. However, since then the necessity of accounting for the effect of shear failure in the phase of seismic design has been gradually realized. In the past years, the performance of bending failure has been deeply investigated [1-6]. For the shear failure of steel pier frames due to the shear local buckling, the experimental investigations have been conducted [7, 8], but the corresponding evaluation method is sparse and specific quantitative criterion to relate these failure modes to steel bridge piers is lacking. Besides, for steel bridge pier frames, both bending and shear failure verifications should be conducted in order to identify which type of failure will occur, especially during earthquake loading [9-11].

The shear failure of column-beam joint in building frames has been regarded as important damage mode [12, 13]. Because of the strengthening measures of pier-girder joint in steel bridge pier frames, large shear deformation may occur at the mid-span of girder [14]. Similar to the previous research [14-18], the strength and ductility should be considered and verified at the same time. A pushover analysis is terminated when any of the structure's failure criterion is satisfied and this state is taken as the ultimate state of the structure, based on which the ductility capacity of the structure can be determined. During the past years, there is a considerable amount of literatures on failure criterion. The bending failure criterion has been deeply studied in previous studies [1, 3-5, 19]. Besides, the shear failure criterion was studied [20, 21]. Although a simple analytical model 
considering shear deformation was discussed by Chusilp and Usami [21], the complete pushover analysis including shear failure for steel bridge pier frames has not been conducted because of the limitation of previous simulation model. The effect of shear failure on the ductility capacity of structure has not been studied in the previous research. In recent years, with the development of computational technology, the strength and ductility including effect of shear deformation and failure can be calculated and predicted accurately and easily. In the previous studies [20, 21], parameter analysis of shear deformation has been done and these results can provide basis for the proposed study. The aim of this study is to provide an analytical model to check and verify the strength and ductility including bending and shear failure modes for steel bridge pier frames more effectively.

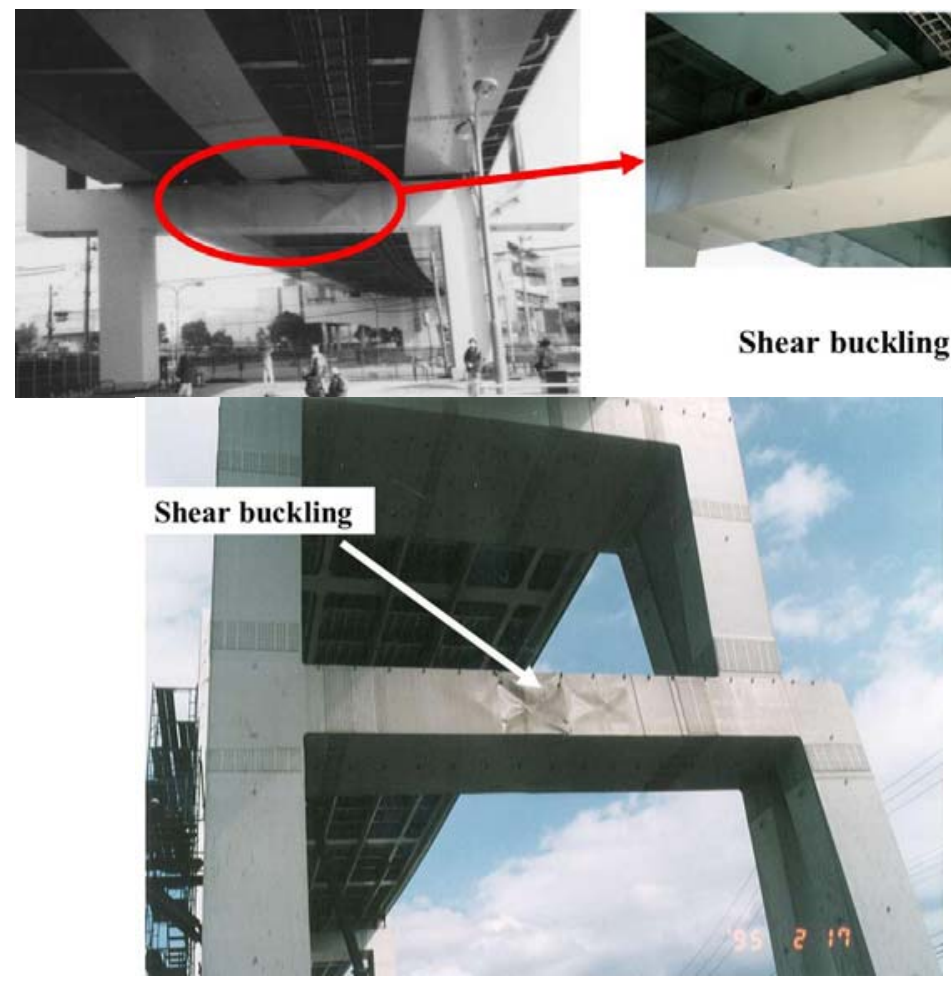

Figure 1. Examples of Shear Failure in Damaged Steel Bridge Pier Frames in the 1995 Kobe Earthquake

Because of the aforementioned lack of verification method about strength and ductility evaluation including shear failure in steel bridge pier frames, a hybrid model including beam, membrane and truss elements is proposed in this paper and a series of pushover analyses are carried out based on this model. First of all, a so-called MB model is established in section 2, in which the details including finite element model, dimensions, cross section, constraint between different elements and so on will be given. Secondly, the previous failure criteria are stated. Furthermore, comparisons between the proposed and previous models' results as well as sensitive parameter analysis are conducted. From the results and discussions, a boundary between bending and shear failure modes is obtained.

\section{FINITE ELEMENT ANALYTICAL MODEL OF STEEL BRIDGE PIER FRAMES}

In this study, the ABAQUS finite element software [22] was utilized to investigate the structural behavior of steel bridge pier frames. Two different finite element analytical models are established, which are BB and MB models, respectively, as shown in Figure 2. In which, the BB model only includes the beam element, and the MB model consists of the membrane and truss elements at the 
mid-span of girder except for the beam element. In the previous study [5], the BB model was employed to evaluate the bending performance of steel structures. In both two models, the P- $\triangle$ effect is taken into account, and the local buckling is ignored. For different models, the effect of shear behavior is taken into account in different ways. In the BB model, the shear deformation is included by using a type of beam element (i.e., B21) based on the Timoshenko beam theory, and the effect of shear failure is not considered. However, in the MB model, the shear deformation is also considered by introducing the membrane element at the mid-span of girder, which can take the effect of shear failure into account. The BB model only with the beam element can't take the effect of shear failure (as shown in Figure 1) into consideration, because the beam element can't accurately simulate the shear buckling occurring at the mid-span of girder. In this study, because the MB model with membrane element at the mid-span of girder can reveal the shear failure more comprehensively and correctly during pushover analysis, the MB model is employed to replace the traditional model (BB model), and the corresponding seismic verification method including the effect of shear failure by using this hybrid analytical model is developed and established.

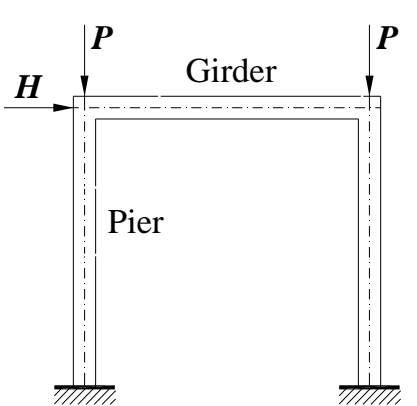

(a) Portal Frame of Steel Bridge Pier

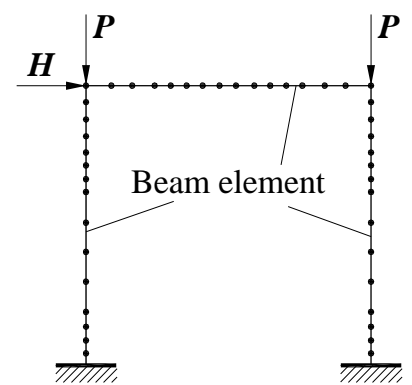

(b) BB Model

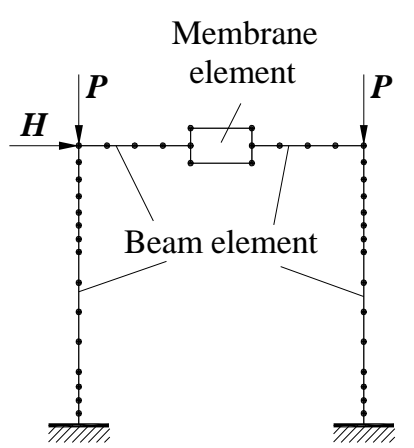

(c) MB Model

Figure 2. Steel Bridge Pier Frame

\subsection{Analytical Model}

\subsubsection{The analytical model only including beam element (BB model)}

The beam element (B21) in ABAQUS, which accounts for the shear deformation based on the Timoshenko beam theory, is utilized in this model, and each of girder and piers is divided into 15 beam elements [23]. Since this type of portal frame is commonly subjected to heavy loading, the plates at the pier-girder connections should be strengthened by doubling the plate thickness in order to avoid shear failure [14].

\subsubsection{The finite element model with membrane element at the mid-span of girder (MB model)}

In this analytical model, the beam element at the mid-span of girder is replaced by the membrane and truss elements. The four-node membrane element (M3D4) in ABAQUS, which has two degrees of freedom at each node, is adopted at the mid-span of girder, and in other parts of beam member the Timoshenko beam element is utilized (same to the BB model). Each pier member is divided into 15 beam elements [23]. The distance between the pier-girder joint and the membrane element is the length of 3 beam elements. Besides, same to the BB model, the plates at the pier-girder connections should be strengthened by doubling the plate thickness in order to avoid shear failure of joints [14]. The only difference between the BB model and MB model is the element type to model the mid-span girder. In order to predict the shear failure mode of steel bridge frame structure, the MB model consists of the membrane and truss elements except for the beam element, and it is then regarded as a hybrid model including three types of elements. 


\subsection{Dimensions of Analytical Model}

In this study, a series of finite element analyses are carried out. As shown in Figure 3, the label of analyzed models (e.g., US35-70A and SS35-40B) is defined as follows. The first letter indicates the type of cross section, where " $U$ " and "S" represent unstiffened box section and stiffened box section, respectively. The following letter S indicates steel bridge pier frame. Accordingly, "US" and "SS" refer to steel bridge pier frames with unstiffened steel box section and stiffened steel box section, respectively. The next two numbers denote the flange width-thickness ratio of column, $R_{f}$, and the web width-thickness ratio of beam, $R_{w b}$, respectively. They are 100 times larger than the actual value. The last letter (A or B) represents the beam length, where "A" means the length of beam is $8300 \mathrm{~mm}$, and " $\mathrm{B}$ " indicates the length is $12450 \mathrm{~mm}$. In other words, the values of $l / h$ in two cases are 0.769 and 1.15 , respectively. Additionally, for some unstiffened cases, in order to evaluate the effect of stiffened measure on the failure mode, stiffeners are employed and "-S" and "-2S" indicate one stiffener and two stiffeners to strengthen the unstiffened specimens, respectively. Some main parameters of finite element analysis are listed in Table 1. Equivalent web width-thickness ratios of beam $R_{w b}$ of $-\mathrm{S}$ and $-2 \mathrm{~S}$ cross sections are given in Table 2. A total of 38 different cases are analyzed in this study.

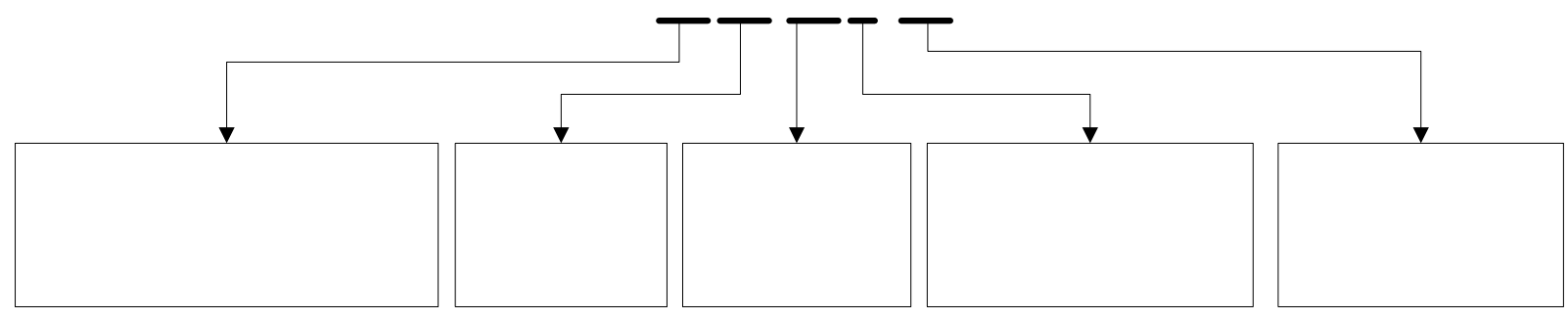

Figure 3. Label of Analytical Cases

Table 1. Main Parameters for Finite Element Analysis

\begin{tabular}{|l|l|}
\hline Parameters & Range \\
\hline Column height, $h(\mathrm{~mm})$ & 10800 \\
\hline Beam length, $l(\mathrm{~mm})$ & 8300,12450 \\
\hline $\begin{array}{l}\text { Flange width-thickness ratio of column, } \\
R_{f}\end{array}$ & $0.35 \sim 0.45$ \\
\hline Web width-thickness ratio of beam, $R_{w b}$ & $0.4 \sim 1.5$ \\
\hline Yield stress of steel (MPa) & 314 \\
\hline Stiffness ratio of column stiffener & 3.0 \\
\hline Stiffness ratio of beam stiffener & 1.0 \\
\hline
\end{tabular}

Table 2. Web Width-thickness Ratio of Beam $R_{w b}$ of -S and -2S Cross Sections

\begin{tabular}{|c|c|c|c|c|}
\hline Specimens & US35-60A-S & US35-70A-S & US35-100A-S & US35-150A-S \\
\hline$R_{w b}$ & 0.313 & 0.372 & 0.573 & 0.860 \\
\hline Specimens & US45-60A-S & US45-70A-S & US45-100A-S & US45-150A-S \\
\hline$R_{w b}$ & 0.308 & 0.363 & 0.540 & 0.811 \\
\hline Specimens & US35-100A-2S & US35-150A-2S & & \\
\hline$R_{w b}$ & 0.591 & 0.549 & & \\
\hline
\end{tabular}




\subsection{Cross Section of Steel Bridge Pier Frame}

For the BB model, the beam element at the mid-span of girder is shown in Figure 4(a). In which, $m, n$ are the two nodes of beam element, and the cross section of pier and girder members are introduced by sectional properties and parameters. For the beam cross sections, the web plate of beam is unstiffened belonging to US model and the web plate of beam is stiffened belonging to SS model. A box section with longitudinal stiffeners (SS model) is one of the most common cross-sectional types used for thin-walled steel structures. In the analysis of such structures, the original stiffened section can certainly be used but, for simplification, an equivalent unstiffened section is introduced [5].

However, in the MB model, the beam element at the mid-span of girder is replaced by membrane and truss elements, as shown in Figure 4(b). It is well-known that shear local buckling may occur at the mid-span of girder. In order to accurately predict the shear failure of steel bridge pier frames, one membrane and two truss elements are introduced into the MB model. The analytical method may be suitable for simulating the in-plane deformation of pushover analysis because the out-of-plane deformation can't be taken into account in membrane element. In addition, the two truss elements are used to model the flange plate at the mid-span of girder because the flange works mainly in tension or compression modes. In the Figure 4(b), $m, n$ are the two nodes of side beam elements, and $i, j, k, l$ are the four nodes of membrane element. Membrane and truss elements share the same nodes, in which $i$ and $j$ are two nodes of one truss element, $l$ and $k$ are two nodes of the other one. The thickness of membrane element is twice of the thickness of web plate based on equivalent cross section method. Cross section area of truss element is equal to that of flange plate of beam.

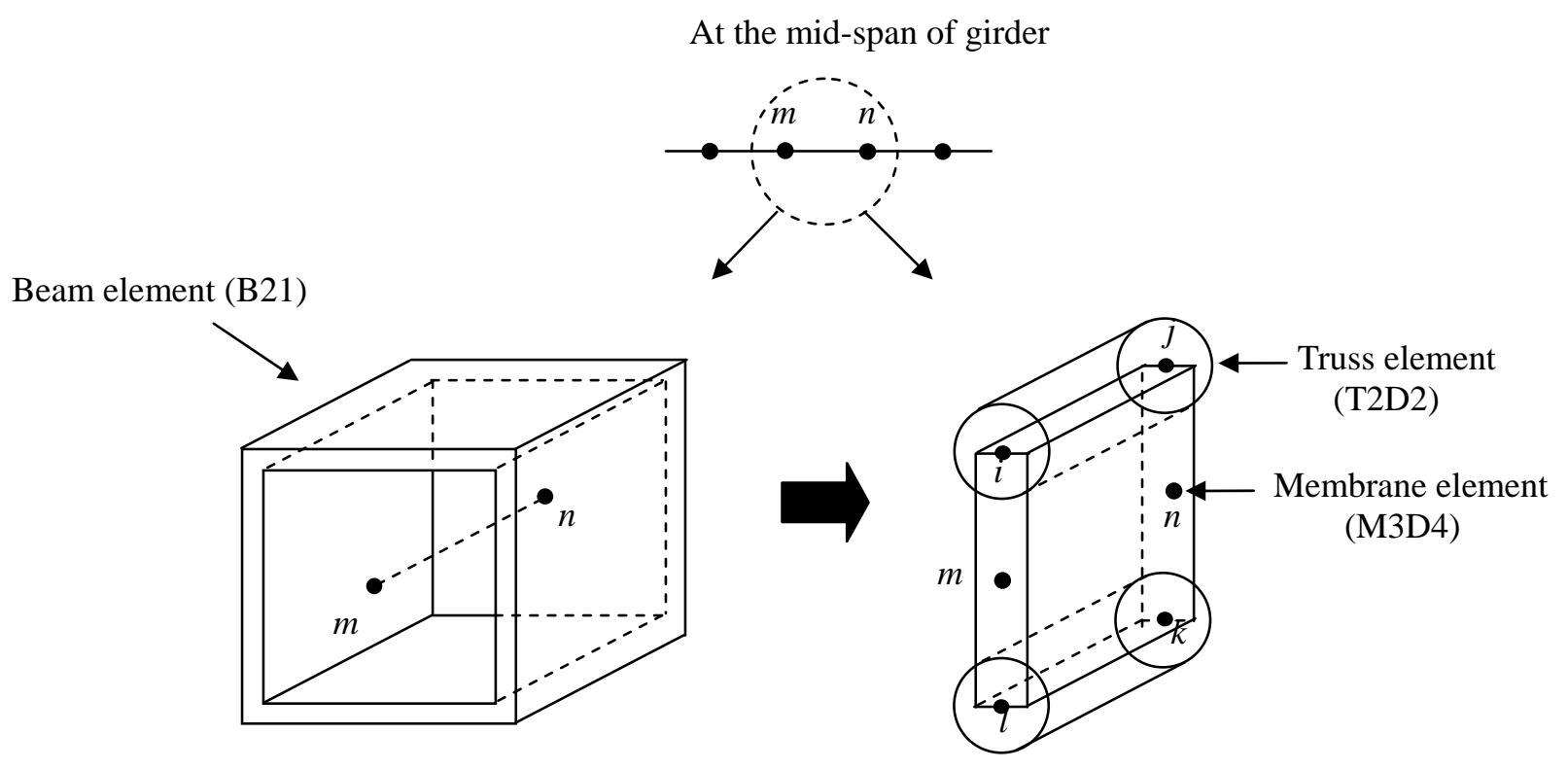

(a) Beam Element of BB Model

(b) Membrane and Truss Elements of MB Model

Figure 4. Difference between BB Model and MB Models 


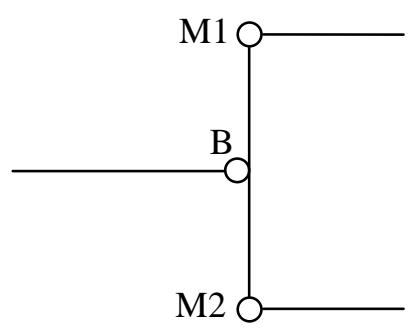

(a) Before Deformation

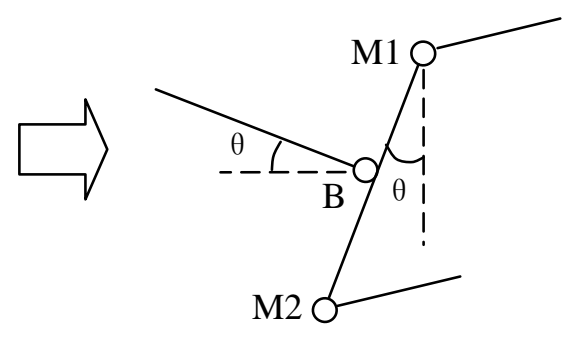

(b) After Deformation

Figure 5. Connection between Membrane and Beam Elements

\subsection{Constraint between Membrane and Beam Elements}

In the proposed analytical model, the connection between membrane and beam elements is established based on the assumption of plane cross section. In Figure 5, B is the node of beam element, and M1 and M2 represent the nodes of membrane element. There are two following constraint conditions:

(1) The length of the connection part (the length between nodes M1 and M2 in Figure 5), which connects membrane element with beam element, is constant;

(2) At the connection part between membrane and beam elements, the rotation of beam element node B is equal to the rotations of the two nodes (M1 and M2) of membrane element.

The displacement relationship between beam and membrane elements can be expressed as follows:

$u_{M}-u_{B}=\left(X_{A}-X_{B}\right)(\cos \theta-1)-\left(Y_{M}-Y_{B}\right) \sin \theta$

$v_{M}-v_{B}=\left(X_{M}-X_{B}\right) \sin \theta+\left(Y_{M}-Y_{B}\right)(\cos \theta-1)$

in which, $u$ and $v$ denote the displacements of $X$-axis and $Y$-axis, respectively. $X, Y$ represent the coordinate magnitudes of $X$-axis and $Y$-axis after deformation, respectively. The subscript $M$ expresses that the variable belongs to membrane element, and the subscript $B$ expresses that the variable belongs to beam element. $\theta$ denotes the rotation of beam element node.

\subsection{Weight of Upper Structure}

In this study, the weight of upper structure is regarded as vertical loads applying on the steel bridge pier frame. Based on the seismic coefficient method [24], the weight of upper structure is calculated. Considering a certain safety coefficient (in this study, is 1.14, same to the reference [23]), the analytical model is subjected to the horizontal load $H=0.2 P$ and the vertical loads of $P$ at the top of the steel bridge pier frame. The weight of upper structure is obtained. The range of $P / P_{y}$ is from 0.28 to 0.5 .

\section{FAILURE CRITERION}

The pushover analysis involves applying monotonic lateral loads to approximately simulate the horizontal displacements of steel bridge pier frames. In somewhat different formats, the pushover analysis has been proposed and evaluated mainly as a demand prediction tool for concrete structures [25-27]. In recent work of the authors [23, 28], the pushover analysis has been proposed for steel frame structures serving for both the capacity evaluation and demand prediction. During 
the pushover analysis, a proper failure criterion is necessary. For RC structures, the failure criterion is usually based on the rotational capacity of plastic hinges. However, the capacity of frame structures composed of thin-walled steel members is mainly controlled by local buckling. In this paper, a failure criterion including bending and shear failure modes is employed to evaluate bending and shear failure modes. Besides, the locations of failure verification, the damage degree and the effective failure length are described in the following sections.

\subsection{Location of Failure Verification}

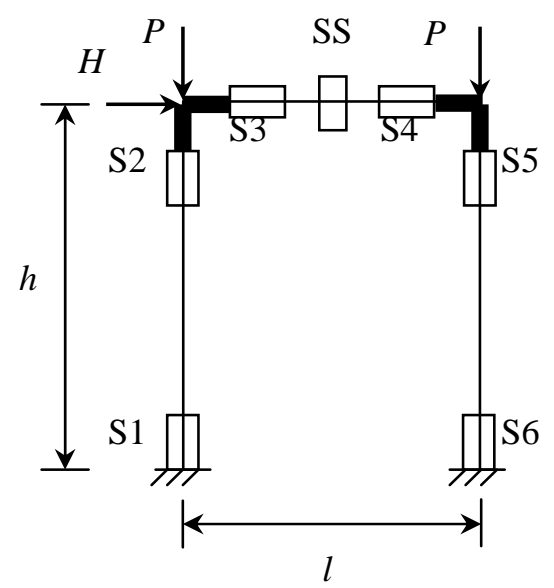

Figure 6. Location of Failure Verification

With the increase of loading, the failure verification locations become wider. Because the steel frame is under combined loading of bending and compression, the compression strain is raised [5]. To completely investigate the bending behavior of steel frames, six bending verification locations (S1 S6) are determined as shown in Figure 6, in which $l$ is the length of girder, $h$ is the height of pier, $P$ and $H$ are vertical and horizontal loads, respectively. Because the stiffness of the pier-girder joint is relatively large (as described in Sections 2.2 and 2.3), in this study, SS at the mid-span of girder is regarded as the shearing verification location, as shown in Figure 6.

\subsection{Failure Verification}

\subsubsection{Bending failure verification}

In the proposed ductility evaluation method, the bending failure criterion can be described by a damage index $D_{s b}$, which is defined:

$D_{s b}=\frac{\varepsilon_{a, s}}{\varepsilon_{u, s}}$

when $D_{s b}$ reaches 1.0 , the bending ultimate state of structure is considered to be attained. Here, $\varepsilon_{a, s}$ represents the average strain of the compressive flange (for the box section) over a certain effective failure length that will be discussed further below. The value $\varepsilon_{u, s}$ denotes the failure strain and, to define it, the empirical formulas obtained from stub-column analyses are employed.

The empirical formulas of the failure strains were proposed for thin-walled steel stub columns with box sections that are subjected to compression and bending. The behavior of box-sectioned stub-columns with and without longitudinal stiffeners has been extensively investigated under combined compression and bending, and corresponding empirical equations for the failure strains were given as follows [5]: 
For unstiffened box stub-columns:

$$
\frac{\varepsilon_{u, s}}{\varepsilon_{y}}=\frac{0.108\left(1-N / N_{y}\right)^{1.09}}{\left(R_{f}-0.2\right)^{3.26}}+3.58\left(1-N / N_{y}\right)^{0.839} \leq 20.0
$$

For stiffened box stub-columns:

$$
\frac{\varepsilon_{u, s}}{\varepsilon_{y}}=\frac{0.8\left(1-N / N_{y}\right)^{0.94}}{\left(R_{f} \cdot \bar{\lambda}_{s}^{0.18}-0.168\right)^{1.25}}+2.78\left(1-N / N_{y}\right)^{0.68} \leq 20.0
$$

in which, $P=$ axial force; $P_{y}=$ squash load; $R_{f}=$ flange width-thickness ratio parameter; and $\bar{\lambda}_{s}=$ stiffener's slenderness ratio parameter. The definitions of $R_{f}$ and $\bar{\lambda}_{s}$ can refer to the reference [19]. In this study, $R_{f}=0.3 \sim 0.7, N / N_{y}=0.0 \sim 0.5$. When the axial force is a tension, it will be taken to be zero.

\subsubsection{Shear failure verification}

In the proposed ductility procedure, the shear failure criterion can be described by a damage index $D_{s s}$, which is defined:

$$
D_{s s}=\frac{\gamma_{s}}{\gamma_{u, s}}
$$

in which, $\gamma_{s}$ is the shearing strain of membrane element, $\gamma_{u, s}$ is the ultimate strain obtained by the equations (7) and (8). Simple formulas are proposed for estimating the ductility capacity of box girders with and without longitudinal web stiffeners as follows [21, 29]:

For unstiffened cross section:

$$
\frac{\gamma_{u, s}}{\gamma_{y}}=\frac{0.142}{\left(R_{w b}-0.18\right)^{4.0}}+4.0 \leq 20.0
$$

For stiffened cross section:

$$
\frac{\gamma_{u, s}}{\gamma_{y}}=2.5+\frac{0.5}{R_{w b}^{6.0}} \leq 20.0
$$

$R_{w b}$ is the web width-thickness ratio of box girders. The limit scope of the equation (8) is $\gamma_{w s} \geq \gamma_{w s}{ }^{*}$, $1.0 \leq \alpha_{w b} \leq 2.0 . \alpha_{w b}$ is the web length-width ratio of the girder. The details can refer to the references [21, 29].

\subsection{Effective Failure Length}

The effective failure length $l_{e}$ of a box-sectioned member adopted in this method is assumed as $l_{e}=$ $\min \left\{0.7 B, l_{d}\right\}$ where $B$ is the flange width and $l_{d}$ is the distance between two adjacent diaphragms [5]. For pipe section stub-columns in compression and bending, an empirical equation for the critical length (i.e., the length giving the lowest strength) was proposed by Gao et al. [3], and this length is found to be about half of the mode length of collapse in local buckling (i.e., the so-called elephant foot bulge) observed in long columns with pipe sections under cyclic lateral loading [30]. 
On this basis, a modified equation (approximately doubling the critical length equation of short cylinders) is employed to define the effective failure length of thin-walled pipe section structures, which is given by Zheng et al. [5]:

$l_{e}=1.2\left(\frac{1}{R_{t}^{0.08}}-1\right) d$

The critical parts could be in more than one place in a framing structure, and all of them should be checked. In a thin-walled steel structure, the excessive deformation tends to intensify in a local part and consequently the redistribution of the stress becomes unexpected. Thus, once the failure criterion at any one of the critical parts is satisfied, the ultimate state of such a structure is thought to be reached.

\section{4. $\quad$ RESULTS AND DISCUSSIONS}

The purpose of this study is to propose an improved analytical model and to evaluate the bending and shear failure modes of steel bridge pier frames by using the proposed model. Therefore, a hybrid model including membrane and truss elements at the mid-span of girder is developed. In this section, first of all, by the comparison of the results between MB and BB models, the reliability of the proposed model is verified. Next, by analyzing the parameters' effect, the relationship between structural parameters and shear failure of steel bridge pier frames is investigated. Finally, by utilizing the proposed method, the cases with stiffened and unstiffened plates are analyzed, and the influences of stiffened measure on the ductility evaluation and failure mode are investigated.

\subsection{Comparison between MB and BB Models' Results}

Table 3. Comparison of Different Models’ Ductility Capacity

\begin{tabular}{|c|c|c|c|c|c|c|c|}
\hline Specimens & $\begin{array}{c}\mathrm{BB} \\
\text { model } \\
\delta_{u b} / \delta_{y}\end{array}$ & $\begin{array}{c}\text { MB } \\
\text { model } \\
\delta_{u b} / \delta_{y}\end{array}$ & $\begin{array}{c}\text { MB } \\
\text { model } \\
\delta_{u s} / \delta_{y}\end{array}$ & Specimens & $\begin{array}{c}\mathrm{BB} \\
\text { model } \\
\delta_{u b} / \delta_{y}\end{array}$ & $\begin{array}{c}\text { MB } \\
\text { model } \\
\delta_{u b} / \delta_{y}\end{array}$ & $\begin{array}{c}\text { MB } \\
\text { model } \\
\delta_{\text {us }} / \delta_{y}\end{array}$ \\
\hline US35-40A & 4.74 & 4.73 & 14.1 & SS35-40A & 3.28 & 3.96 & 8.67 \\
\hline US35-50A & 4.65 & 4.71 & 6.14 & SS35-50A & 3.37 & 3.82 & 9.50 \\
\hline US35-60A & 4.48 & 4.72 & 3.37 & SS35-60A & 3.22 & 3.52 & 7.13 \\
\hline US35-70A & 4.25 & 4.84 & 2.78 & SS35-70A & 3.22 & 3.28 & 4.85 \\
\hline US35-100A & 3.40 & 4.45 & 2.70 & SS45-40A & 2.48 & 2.53 & 6.07 \\
\hline US35-150A & 3.42 & 4.95 & 2.01 & SS45-50A & 2.34 & 2.36 & 5.98 \\
\hline US45-40A & 2.93 & 2.92 & 6.86 & SS45-60A & 2.34 & 2.34 & 4.85 \\
\hline US45-50A & 2.81 & 2.93 & 4.02 & SS45-70A & 2.34 & 2.34 & 3.59 \\
\hline US45-60A & 2.75 & 2.97 & 2.53 & SS35-40B & 3.99 & 3.96 & 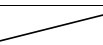 \\
\hline US45-70A & 2.63 & 2.90 & 2.03 & SS35-50B & 3.55 & 3.55 & 18.97 \\
\hline US45-100A & 2.50 & 2.89 & 1.90 & SS35-60B & 3.57 & 3.53 & 11.09 \\
\hline US45-150A & 2.47 & 3.03 & 1.41 & SS35-70B & 3.53 & 3.49 & 7.92 \\
\hline US35-60A-S & 4.53 & 4.50 & 27.9 & SS45-40B & 2.66 & 2.63 & 24.4 \\
\hline US35-70A-S & 4.21 & 4.20 & 19.1 & SS45-50B & 2.57 & 2.55 & 14.7 \\
\hline US35-100A-S & 3.42 & 3.94 & 7.65 & SS45-60B & 2.47 & 2.42 & 7.26 \\
\hline US35-150A-S & 3.49 & 4.56 & 2.43 & SS45-70B & 2.43 & 2.42 & 4.97 \\
\hline US45-60A-S & 2.74 & 2.74 & 12.9 & & & & \\
\hline US45-70A-S & 2.66 & 2.72 & 9.33 & & & & \\
\hline US45-100A-S & 2.47 & 2.61 & 5.72 & & & & \\
\hline US45-150A-S & 2.51 & 2.87 & 1.96 & & & & \\
\hline US35-150A-2S & 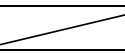 & 4.45 & 5.93 & & & & \\
\hline US45-150A-2S & 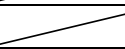 & 2.83 & 4.79 & & & & \\
\hline
\end{tabular}

Notes: Gray section means the minimum value between $\delta_{u b} / \delta_{y}$ and $\delta_{u s} / \delta_{y}$ of MB model. 
The computational results for the case of US35-70A by using MB and BB models are shown in Figure 7. Firstly, Figure 7(a) indicates the horizontal load versus horizontal displacement curves obtained from the MB and BB models. It demonstrates the relationship between $H / H_{y}$ ( $H$ is the horizontal load, $H_{y}$ is the horizontal yield load) and $\delta / \delta_{y}$ ( $\delta$ is the horizontal displacement, $\delta_{y}$ is the horizontal yield displacement) for the steel bridge pier frames. Secondly, Figure 7(b) illustrates the damage degree of steel frame versus horizontal displacement curves obtained from the finite element analysis of MB model. In Figure 7(b), the damage degrees of S2 S4 (S1 S6 are six locations of failure verification as shown in Figure 6) are relatively small, and then the magnitudes of S2 S4 are omitted in Figure 7(b). Lastly, Figure 7(c) demonstrates the damage degree versus horizontal displacement curves of the BB model. Table 3 reveals the ductility capacity of all the analytical examples obtained from finite element analyses of BB and MB models. $\delta_{u b} / \delta_{y}$ and $\delta$ us $/ \delta$ y represent the ratios of bending and shear ultimate-to-yield horizontal displacements, respectively. In this study, they are termed as the bending ductility and shear ductility, respectively.

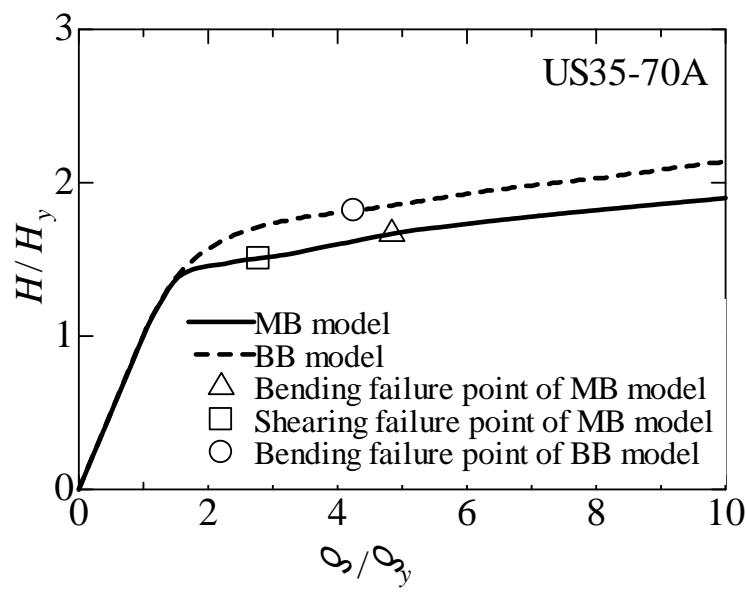

(a) Horizontal Load-displacement Curves and Failure Points of MB and BB Models

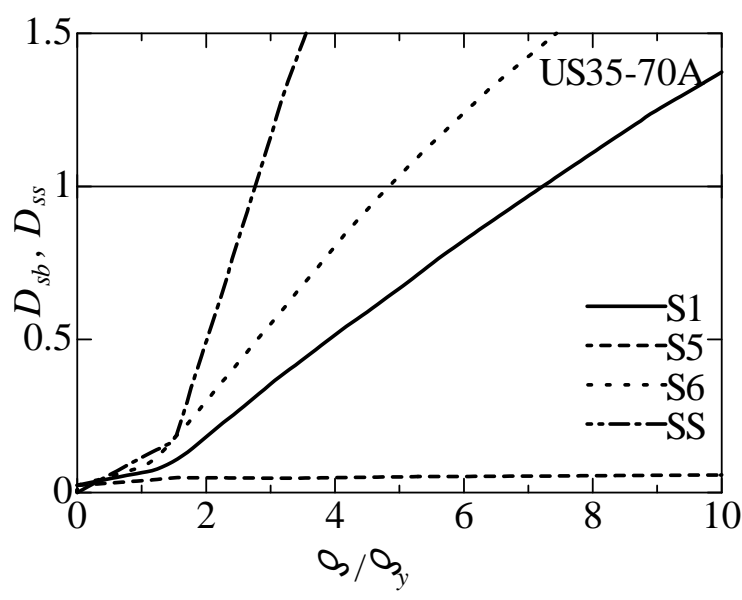

(b) Damage degree of MB Model 


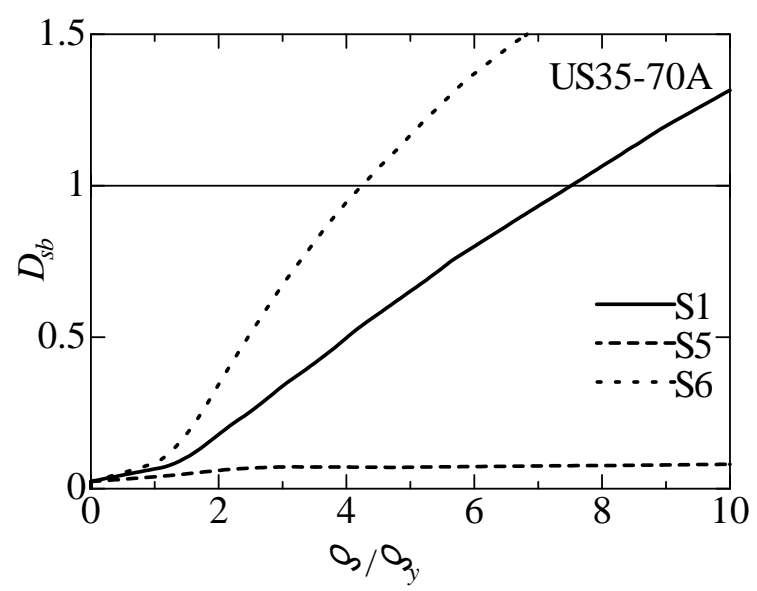

(c) Damage Degree of BB Model

Figure 7. Horizontal Load Displacement Curves and Damage Degree of MB and BB Models

Based on the analytical results of US35-70A as shown in Figure 7, the web width-thickness ratio of beam is comparatively large, and shear failure is predicted to occur at the mid-span of girder. Figure 7(a) reveals that the shear failure occurs before bending failure during the pushover analysis of MB model, and the steel frame may encounter shear failure firstly. Besides, the horizontal displacements of the MB model in this study are larger than that of BB model obtained from the previous method, which is used to evaluate the bending performance. From the analytical responses of Figure 7(b), we can observe that the shear damage degree of SS increases more quickly than the bending damage degree of other locations. Individual differences in simulation results may reflect differences in analytical models, specifically in the damage degree and horizontal displacement. In conclusion, the previous method, which only consists of beam element, can't be employed to predict the shear failure of steel bridge pier frames.

Furthermore, some differences may exist in the load-displacement curves between $\mathrm{MB}$ and $\mathrm{BB}$ models as shown in Figure 7. On one hand, when the magnitude of $\delta$ is near to $1.7 \delta_{y}$, the strength of BB model increases continuously and smoothly, however, for MB model the same phenomenon does not exist. It demonstrates that the web plate at mid-span of MB model's girder has reached the ultimate shear state. Because the shear failure mainly results in the horizontal displacement of steel frames, the strength increase will be delayed. On the other hand, the bending failure points obtained from $\mathrm{MB}$ and $\mathrm{BB}$ models are different. The large width-thickness ratio parameter leads to the decrease of shearing strength, and meanwhile the bending plastic damage may be delayed during the bending verification procedure because of the relatively large bending plastic deformation capacity. Consequently, for the cases of shearing beam with large width-thickness ratio parameter, the prediction precision of its failure mode will be improved by using the proposed method in this study.

\subsection{Effect of Web Width-thickness Ratio of Beam $\boldsymbol{R}_{w b}$}

Relationships between horizontal displacement and web width-thickness ratio of beam, $R_{w b}$, are illustrated in Figure 8. The shear ductility capacity of steel bridge pier frames is evaluated, and can be expressed as $\delta_{\text {us }} / \delta_{y}$. The results of unstiffened and stiffened models are shown in Figure 8, from which it is observed that the shear ductility decreases with the increase of $R_{w b}$. The similar conclusion is obtained from the previous research [20,21]. From the results of Figure 8, the shear ductility capacity of the examples with the flange width-thickness ratios of column $R_{f}=0.35$ is relatively larger compared with the examples with $R_{f}=0.45$. Based on the stiffness matching theory, for these analytical examples, the web width-thickness ratio of beam corresponding to large flange 
width-thickness ratio of column should be relatively large. Accordingly when the magnitude of model's $R_{f}$ is equal to 0.45 , its $R_{w b}$ should be relatively large. In other words, when the web plate of beam is thick, the shear ductility capacity of steel bridge pier frames might be large. The similar conclusion has been demonstrated in the previous study [20].

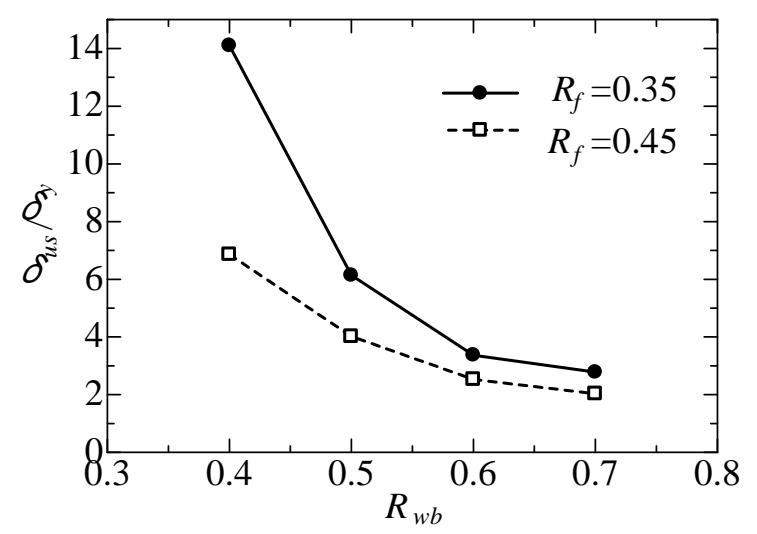

(a) Unstiffened Cross Section

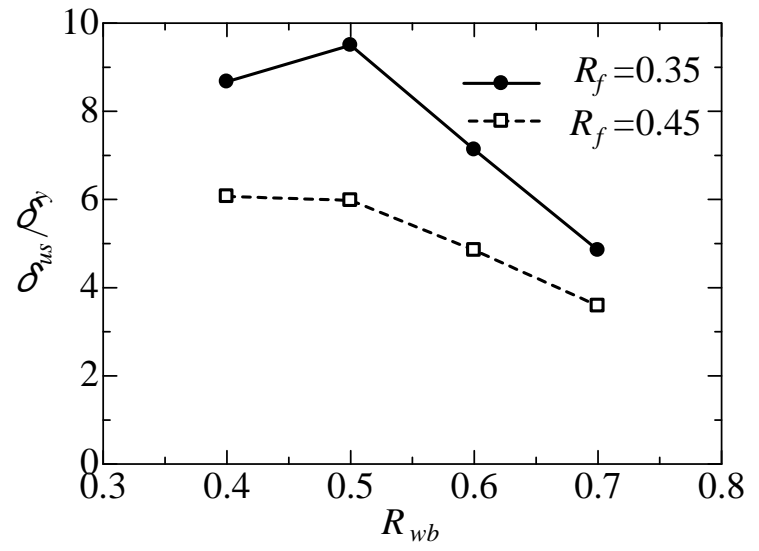

(b) Stiffened Cross Section $(l / h=0.769)$

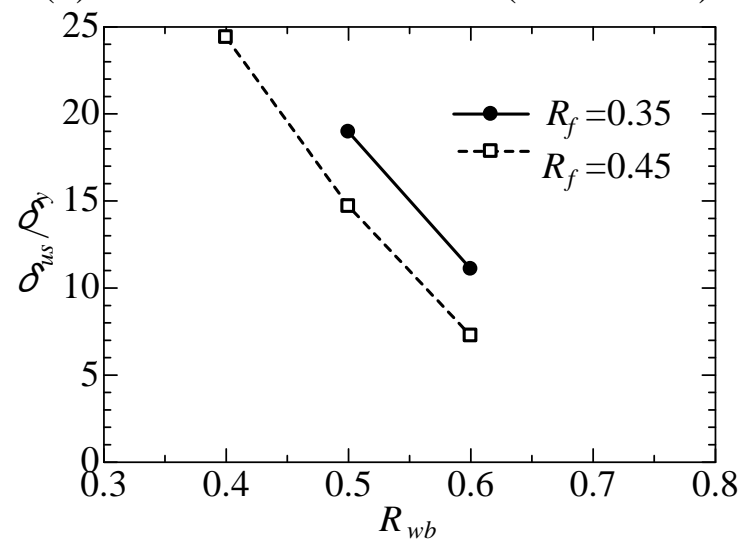

(c) Stiffened Cross Section $(l / h=1.15)$

Figure 8. Effect of Web Width-thickness Ratio of Beam, $R_{w b}$, on Shear Ductility Capacity of Steel Frames

\subsection{Comparison between Bending and Shear Failure Modes}

The horizontal displacements versus web width-thickness ratio of beam $R_{w b}$ curves are illustrated in Figure 9 obtained from the unstiffened cases. It is observed that the bending ductility of unstiffened structures decreases with the increase of $R_{w b}$, however, the shear ductility basically 
retains constant with the increase of $R_{w b}$. When $R_{w b}$ is larger than 0.6, although the ultimate bending displacement is near to the ultimate shear displacement, the first appearance of shear failure should not be ignored. In Figure 9, when $R_{w b}$ is equal to 0.4 and 0.5 , the bending failure occurs before the shear failure, but on the contrary when $R_{w b}$ is equal to $0.6 \sim 1.5$, the shear failure occurs before the bending failure. From the point of view of structural ductility, when $R_{w b}$ is equal to 0.4 and 0.5 , shear ductility is better than bending ductility, but when $R_{w b}$ is equal to $0.6 \sim 1.5$, the opposite is true. Figure 10 indicates the ultimate displacements $\delta_{u} / \delta_{y}$ of steel bridge pier frames, which combines the bending and shear cases. In Figure 11, all of computational results are given in the same figure. The solid and black mark means bending failure, and the hollow and white one means shear failure. For the cases with stiffened cross section, the bending failure is dominant. On the other hand, for the cases with unstiffened cross section, the shear failure plays a critical role when $R_{w b}$ is from 0.6 to 1.5. The above findings indicate that we can make a judgment between bending and shear failure modes by the magnitude of $R_{w b}$, and the approximate boundary of $R_{w b}$ is 0.6. Generally a pier frame may be designed to avoid the occurrence of shear failure. Therefore, its $R_{w b}$ should be less than 0.6. In this study, for some stiffened cases, the stiffener plates make the shear failure risk decrease, and for the unstiffened cases, maybe the shear failure occurs firstly when $R_{w b}$ is greater than 0.6. Consequently, the unstiffened cases should be verified and analyzed, and some stiffened measures for avoiding occurrence of shear failure should be taken into account. The discussions will be carried out deeply in following section 4.4.

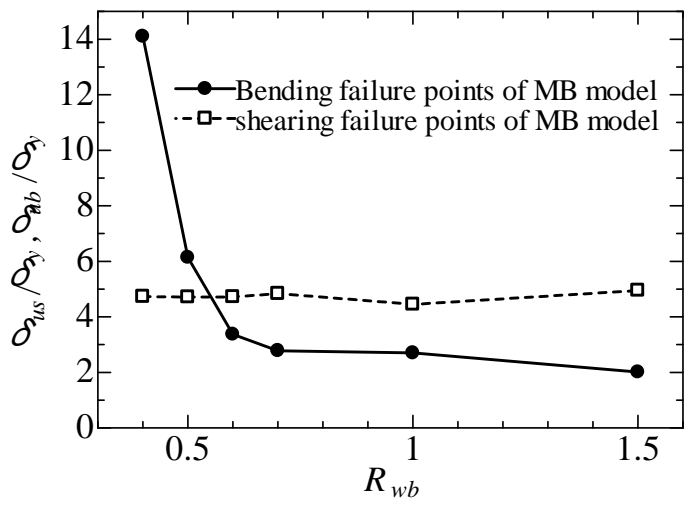

(a) US35-A Series

Figure 9. Comparison between Bending and Shear Failure Points

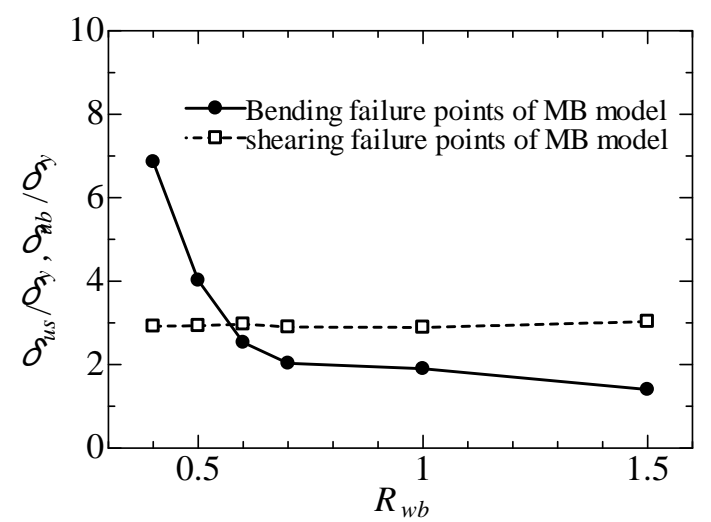

(b) US45-A Series (b) US45-A Series

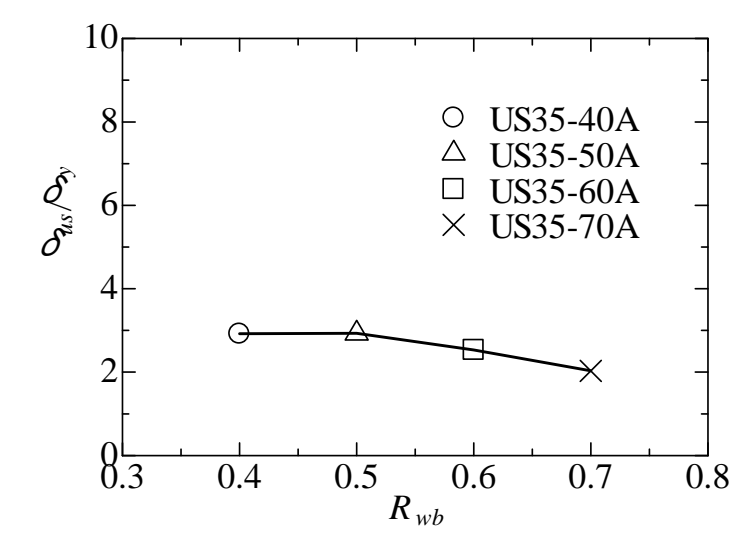

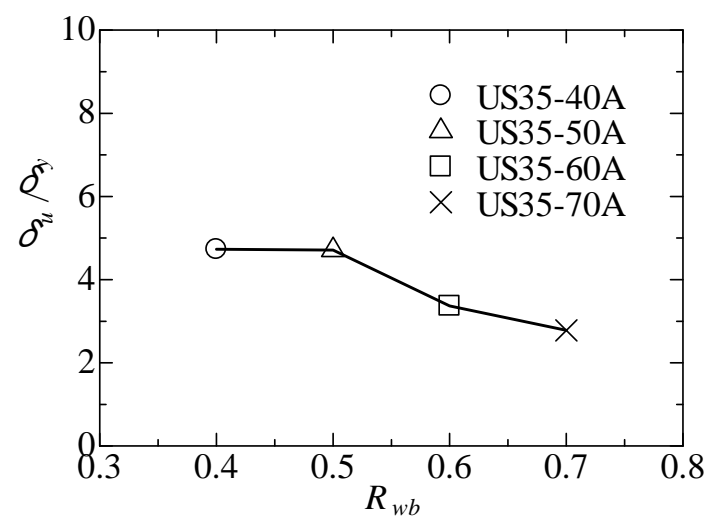

(a) US35-A Series
Figure 10. Ductility Capacity Combining Bending and Shearing Cases 


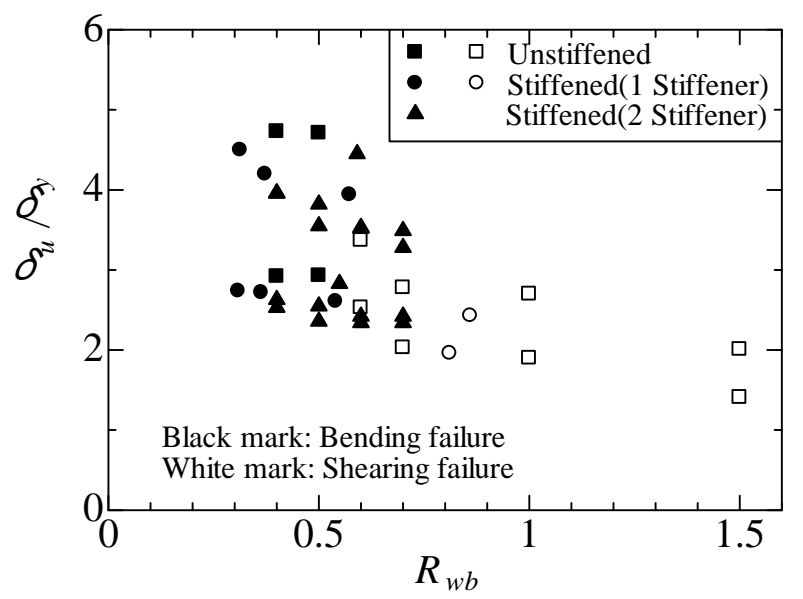

Figure 11. Relationship between Failure Modes (Bending and Shear Failure Modes) and Web Width-thickness Ratio of Beam $R_{w b}$

\subsection{Performance of Steel Frames with and without Stiffeners}

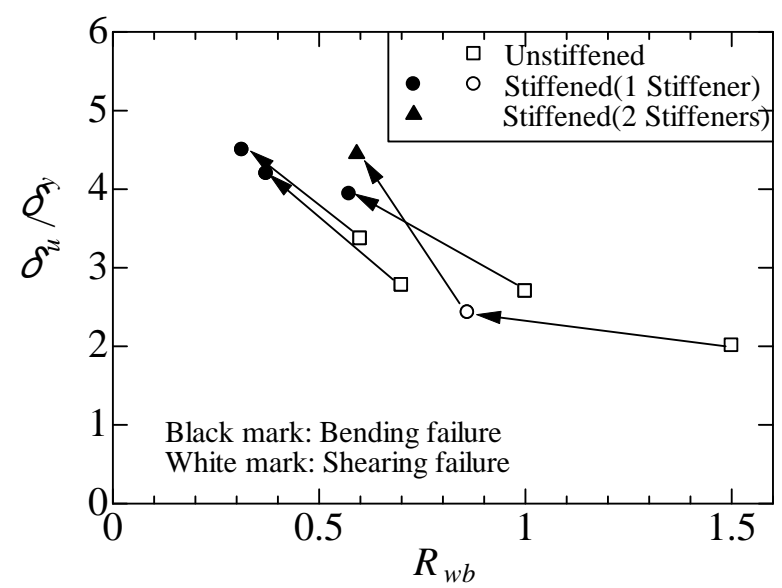

(a) $R_{f}=0.35$

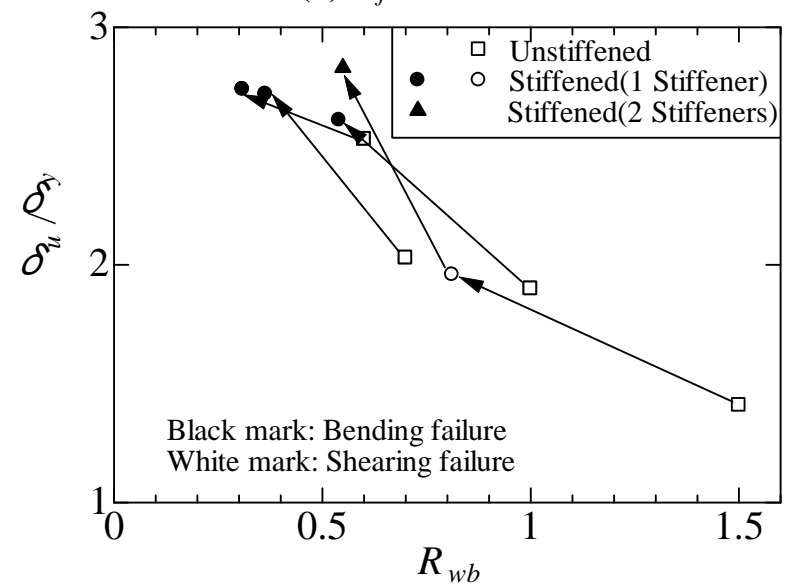

(b) $R_{f}=0.45$

Figure 12. Effect of Stiffener Plate on Failure Modes

Ductility evaluation of US35-60A 150A and US45-60A 150A conducted above reveals that their shear failure is dominant, and some stiffener measures should be taken to avoid shear failure. In order to investigate the effect of stiffener measures on the failure mode for steel frames, the analytical cases with and without stiffeners are conducted. The ultimate displacements $\delta_{u} / \delta_{y}$ versus web width-thickness ratio of beam $R_{w b}$ curves are shown in Figure 12. The figure 
illustrates how to improve ductility capacity, and how the failure mode translates from bending to shear failure by taking some stiffened measures. The flange width-thickness ratios $R_{f}$ of column and beam are 0.35 and 0.45 in Figure 11(a) and Figure 12(b) (ductility capacity), respectively. The following demonstrates and explains these figures.

(1) When the flange width-thickness ratio $R_{f}$ of column is 0.35 and 0.45 , the failure mode changes from shear to bending failure at $R_{w b}=0.6$, for $R_{w b}=1.0,0.7,0.6$, respectively. This discussion dose not include the case of $R_{w b}=1.5$, which has the thinnest web plate. Although for some stiffened cases in above analyses, shear failure will appear firstly when $R_{w b}>0.8, R_{w b}=0.6$ is regarded as the boundary from shear failure to bending failure, as described above.

(2) When the flange width-thickness ratio $R_{f}$ of column is 0.35 , its ductility capacity is more better than the case of $R_{f}=0.45$. The main reason of this result is that bending failure is dominant if the flange width-thickness ratio is relatively small.

Next, for the cases with the thinnest web plate, every web plate has two stiffeners. The web width-thickness ratio of beam $R_{w b}=0.591 \quad\left(R_{f}=0.35\right)$ and $R_{w b}=0.549 \quad\left(R_{f}=0.45\right)$, respectively. These computational results are given in Figure 12. The model with two stiffeners has undergone bending failure. The ductility capacity has been improved greatly.

Different marks refer to different stiffened sections as shown in Figures. 11 and 12. From these results, shear failure is prone to occur when $R_{w b}>0.6$. For this reason, in this study, the magnitude 0.6 of web width-thickness ratio of beam is regarded as the key parameter of identifying different failure types.

\section{SUMMARY AND CONCLUSIONS}

In this paper, a more accurate analytical method considering the effect of shear failure at the mid-span of girder was proposed to investigate the ductility performance of steel bridge pier frames. Different two simulation models, namely BB and MB models, were employed to evaluate the ductility and failure behavior of steel bridge pier frames. In the proposed MB model, membrane and truss elements were introduced. Moreover, comparisons between MB and BB models' results were carried out and parameter effect investigation was conducted. From the above discussions, we can draw the following conclusions:

(1) Comparison between the previous BB model's and the proposed MB model's results has been conducted in this study. The deformation of MB model is larger than that of BB model. The traditional method using the BB model cannot accurately take shear failure at mid-span of girder into account. However, in some cases the effect of shear failure on ductility capacity of steel frames should not be ignored, especially for the cases with large web width-thickness ratio of beam.

(2) Because shear failure is one of the main failure modes of the cases with unstiffened web plate of beam, the finite element analysis using the MB model is necessary. Compared with the $\mathrm{BB}$ model, the MB model can accurately predict the shear failure of steel bridge pier frames. When the bending failure is dominant, the proposed analysis method in this paper shows acceptable agreement with the previous method.

(3) The stiffener of beam web plate can greatly improve ductility capability of structures.

(4) The magnitude of beam web width-thickness ratio (0.6) is the key parameter of identifying different failure types (bending and shear failure modes). 
(5) The strength and ductility evaluation method of steel bridge pier frames can be effectively used to study the effects of various structural parameters which will be very useful in establishing design guidelines.

\section{ACKNOWLEDGMENT}

The first author is the post doctor researcher of Meijo University at Nagoya, Japan, who is supported by the Daiko Foundation. The author would like to thank to the Daiko Foundation for their financial assistance.

\section{REFERENCES}

[1] Nishikawa, K., Yamamoto, S., Natori, T., Terao, O., Yasunami, H., Terada, M., "An Experimental Study on Improvement of Seismic Performance of Existing Steel Bridge Piers", Journal of Structural Engineering, JSCE, 1996, Vol. 42, No. A, pp. 975-986 (in Japanese).

[2] White, D.W., Barth, K.E., "Strength and Ductility of Compact-flange I-girders in Negative Bending", Journal of Constructional Steel Research, 1998, Vol. 45, No. 3, pp. 241-280.

[3] Gao, S., Usami, T., Ge, H.B., "Ductility of Steel Short Cylinders in Compression and Bending", Journal of Engineering Mechanics, ASCE, 1998, Vol. 124, No. 2, pp. 176-183.

[4] Nishikawa, K., Murakoshi, J., Takahashi, M., Okamoto, T., Ikeda, S., Morishita, H., "Experimental Study on Strength and Ductility of Steel Portal Frame Pier", Journal of Structural Engineering, JSCE, 1999, Vol. 45, No. A, pp. 235-244 (in Japanese).

[5] Zheng, Y., Usami, T., Ge, H.B., "Ductility Evaluation Procedure for Thin-walled Steel Structures", Journal of Structural Engineering, ASCE, 2000, Vol. 126, No. 11, pp. 1312-1319.

[6] Susantha, K., Aoki, T., Kumano, T., Yamamoto, K., "Applicability of Low-yield-strength Steel for Ductility Improvement of Steel Bridge Piers", Engineering Structures, 2005, Vol. 27, No. 7, pp. 1064-1073.

[7] Hirano, T., Nishioka, T., Takada, Y., Yoshikawa, N., Matsuda, Y., "Report on Shear Strength of Web Panel in Cross Beam of Rigid Framed Steel Pier", Steel Construction Engineering, JSSC, 2006, Vol. 14, No. 11, pp. 527-534 (in Japanese).

[8] Miki, T., Yamada, O., Higuchi, N., "An Experimental Study on Elasto-plastic Behavior of Steel Web Plates under Cyclic Shearing Force", Journal of Structural Engineering, JSCE, 2007, Vol. 53, No. A, pp. 117-124 (in Japanese).

[9] Shen, Z., Zhang, Q., "Interaction of Local and Overall Instability of Compressed Box Columns", Journal of Structural Engineering, ASCE, 1991, Vol. 117, No. 11, pp. 3337-3355.

[10] Chan, S.L., Kitipornchai, S., Al-Bermani, F.G.A., "Elasto Plastic Analysis of Box Beam Columns Including Local Buckling Effects", Journal of Structural Engineering, ASCE, 1991, Vol. 117, No. 7, pp. 1946-1962.

[11] Fukumoto, Y., Uenoya, M., Nakamura, M., Kobayashi, Y., "Strength and Ductility of Plate Girder Panels under Cyclic Shear", Journal of Structural Engineering, JSCE, 2000, Vol. 46, No. 1, pp. 143-150 (in Japanese).

[12] Krawinkler, H., Popov, E.P., Bertero, V.V., "Shear Behavior of Steel Frame Joints", Journal of the Structural Division, ASCE, 1975, Vol. 101, No. 11, pp. 2317-2336.

[13] Ghobarah, A., Said, A., "Shear Strengthening of Beam-column Joints", Engineering Structures, 2002, Vol. 24, No. 7, pp. 881-888.

[14] Chen, Z.Y., Ge, H.B., Kasai, A., Usami, T., "Simplified Seismic Design Approach for Steel Portal Frame Piers with Hysteretic Dampers", Earthquake Engineering \& Structural Dynamics, 2007, Vol. 36, No. 4, pp. 541-562. 
[15] Nakamura, H., "Formulae for Evaluating Shear-bending Buckling Strength of Steel Piers with Circular Cross Section and Applicability of the Numerical Buckling Analysis Method", Proceedings of Nonlinear Numerical Analysis and Seismic Design of Steel Bridge Piers, Japan, 1997, Vol. 1, pp. 37-42 (in Japanese).

[16] Lee, S.C., "Strength of Plate Girder Web Panels under Pure Shear", Journal of Structural Engineering, ASCE, 1998, Vol. 124, No. 2, pp. 184-194.

[17] Morishita, N., Mori, H., Maeno, H., Okamoto, T., Nanoka, T., Usami, T., "Seismic Design of Steel Bridge Pier Frames Considering Shear Local Buckling in Beam Member", Proceedings of the 6th Symposium on Ductility Design Method for Bridges, Tokyo, 2003, Vol. 1, pp. 293-298 (in Japanese).

[18] Susantha, K.A.S., Aoki, T., Kumano, T., "Strength and Ductility Evaluation of Steel Bridge Piers with Linearly Tapered Plates", Journal of Constructional Steel Research, 2006, Vol. 62, No. 9, pp. 906-916.

[19] Zheng, Y., Usami, T., Ge, H.B., "Ductility of Thin-walled Steel Box Stub-columns", Journal of Structural Engineering, ASCE, 2000, Vol. 126, No. 11, pp. 1304-1311.

[20] Chusilp, P., Usami, T., "Strength and Ductility of Steel Box Girders under Cyclic Shear", Journal of Structural Engineering, ASCE, 2002, Vol. 128, No. 9, pp. 1130-1138.

[21] Chusilp, P., Usami, T., "New Elastic Stability Formulas for Multiple-stiffened Shear Panels", Journal of Structural Engineering, ASCE, 2002, Vol. 128, No. 6, pp. 833-836.

[22] ABAQUS, "ABAQUS/Analysis User's Manual-version 6.6", ABAQUS, Inc.: Pawtucket, RI, 2006.

[23] Usami, T., Zheng, Y., Ge, H.B., "Seismic Design Method for Thin-walled Steel Frame Structures", Journal of Structural Engineering, ASCE, 2001, Vol. 127, No. 2, pp. 137-144.

[24] JRA, "Specifications for Highway Bridges, Part V", Japanese Road Association, 1996 (in Japanese).

[25] Saiidi, M., Sozen, M.A., "Simple Nonlinear Seismic Analysis of R/C Structures", Journal of the Structural Division, ASCE, 1981, Vol. 107, No. 5, pp. 937-953.

[26] Collins, K.R., Wen, Y.K., Foutch, D.A., "Dual-level Sesmic Design: a Reliability-based Methodology", Earthquake Engineering \& Structural Dynamics, 1996, Vol. 25, No. 12, pp. 1433-1467.

[27] Bracci, J.M., Kunnath, S.K., Reinhorn, A.M., "Seismic Performance and Retrofit Evaluation of Reinforced Concrete Structures", Journal of Structural Engineering, ASCE, 1999, Vol. 123, No. 1, pp. 3-10.

[28] Zheng, Y., Usami, T., Ge, H.B., "Seismic Response Predictions of Multi-span Steel Bridges through Pshover Aalysis", Earthquake Engineering \& Structural Dynamics, 2003, Vol. 32, No. 8, pp. 1259-1274.

[29] Chusilp, P., Usami, T., Ge, H.B., Maeno, H., Aoki, T., "Cyclic Sear Bhaviour of Seel Bx Grders: Eperiment and Aalysis", Earthquake Engineering \& Structural Dynamics, 2002, Vol. 31, No. 11, pp. 1993-2014.

[30] Gao, S., Usami, T., Ge, H.B., "Ductility Ealuation of Seel Bidge Pers with Ppe Sctions", Journal of Engineering Mechanics, ASCE, 1998, Vol. 124, No. 3, pp. 260-267. 